\title{
Support and Compliance with 20mph Speed Limits in Great Britain
}

\section{Introduction}

The prevalence of $20 \mathrm{mph}$ speed limits across Great Britain (and 30kph limits across much of Europe) is increasing. In Great Britain, by 2014 approximately $20 \%$ of the country's residential streets already had signed $20 \mathrm{mph}$ limits, and many more schemes are planned. However, while public support for speed limits generally is typically very high, lack of compliance with the limits by drivers is often a cause for concern. In general, there are a number of challenges to the support of, and compliance with, speed limits. These include awareness and appreciation of the benefits of low speeds; the contested risks posed by speeding; the tendency of drivers to over-estimate their own driving skill compared to other drivers; and the tendency for driving to become an automatic, habitual practice with low attention levels placed upon it, with the consequent 'accidental' breaking of speed limits. While these issues are increasingly well understood academically, an in-depth study of how they apply to low speed residential street limits has yet to be undertaken. Such a study was therefore completed by the authors and is the subject of this paper.

The factors affecting lack of compliance may be complex, but the bottom line seems to be an incongruence between attitudes to speeding (general disapproval), and behaviour (general speeding). In a classic study of 'do as I say, not as I do', the United States based AAA foundation (2012) found that while $89 \%$ of drivers did not approve of speeding on residential roads, $46 \%$ said they had driven $10 \mathrm{mph}$ over the speed limit on a residential street in the past month. In Britain much the same effect seems present: a Department for Transport (2012) survey found 91\% agreed that people should drive within the speed limit, but the Department for Transport's 'free flow' figures (2012b) obtained from automatic traffic counters reported that $47 \%$ of cars exceeded $30 \mathrm{mph}$ speed limits, with $16 \%$ travelling at $35 \mathrm{mph}$ or more.

The nature of these complexities within the context of the increased importance of residential area speed limits provide the setting for the research reported here. Using a large survey of GB adults, the authors investigated the relationship between support/opposition and compliance/noncompliance with $20 \mathrm{mph}$ speed limits. The focus in this paper is on drivers; the findings are reported and then discussed in the light of the probable need for additional measures to encourage pro-social driving behaviours.

Key questions asked included:

- What levels of support/opposition can be expected amongst drivers for $20 \mathrm{mph}$ limits in GB, and what are the reasons for this support/opposition?

- What levels of driving compliance with $20 \mathrm{mph}$ limits can be expected and what factors underpin these likely compliance levels?

- How well do attitudes and behaviours align?

The paper first reviews the underlying factors affecting support and compliance with speed limits. We then outline the methodology and summarise the key data. The discussion then focuses on implications and possible behaviour change interventions aimed at drivers. 


\section{Literature Review}

\subsection{The rise of $20 \mathrm{mph}$ and $30 \mathrm{kph}$ limits: policy and practice context}

Reducing speeds within $20 \mathrm{mph}$ or $30 \mathrm{kph}$ residential area speed limits is contended as generating considerable benefits. Advocates of $20 \mathrm{mph}$ limits argue they are a mechanism for redefining urban spaces as pleasant places to live rather than as 'roads for cars' (Tranter 2010). Evidence from small scale $20 \mathrm{mph}$ or $30 \mathrm{kph}$ zones (zones are traffic calmed; this paper is concerned with signs-only $20 \mathrm{mph}$ limits) indicates how low traffic speeds can encourage higher community benefits in health, wellbeing and social capital (Dorling 2014; McCabe, Schoneman and Arcaya 2013; Elvik 2012; Pilkington 2009), and encouragement of healthier and more sustainable transport modes such as walking and cycling (Cohen, Boniface and Watkins 2014). Zones can also deliver impressive speed reductions and associated road danger reduction: Grundy, Steinbach, Edwards, Green, Armstrong and Wilkinson's (2009) review of $20 \mathrm{mph}$ zones in London calculated a $40 \%$ reduction in casualties, while Pilkington's earlier (2000) review of $20 \mathrm{mph}$ zones demonstrated an average speed reduction of $9.3 \mathrm{mph}$ and an associated reduction in crashes of $60 \%$.

These benefits tend to be located within a public health rather than, say, an economic perspective, but they appear to be increasingly acknowledged within government policy, in particular within Europe. For example, while setting speed limit policies remains the domain of national government, the Koch Report (2011) recommended EU wide implementation of $30 \mathrm{kph}$ limits in residential areas. More recently a European Citizens' Initiative has recently been launched calling for a default 30 $\mathrm{km} / \mathrm{h}$ speed limit in residential areas across the EU. Within the UK there is increasing local authority enthusiasm for $20 \mathrm{mph}$ limits and this local pressure emboldened the UK Department for Transport (2013) to 'consider the introduction of more $20 \mathrm{mph}$ limits and zones, over time, in urban areas and built-up village streets that are primarily residential'. However they warn that 'successful $20 \mathrm{mph}$ speed limits are generally self-enforcing' and 'to achieve compliance there should be no expectation on the police to provide additional enforcement beyond their routine activity, unless this has been explicitly agreed'.

It remains to be seen if signs-only speed limits will deliver the same outcomes as zones. International evidence across various speed limits and suggests compliance will be a serious challenge. Islam, ElBasyouny, and Ibrahim (2013) reviewed speed limit reductions in urban areas across the world and found vehicle speed reductions in urban interventions to be variable but typically 1-3kph in size. Similar speed reductions of about $2 \mathrm{kph}$ were reported in Swedish cities by Hyden, Jonsson, Linderholm and Towliat (2008). In Graz, Austria, a 30kph trial limit between 1992 and 1994 again yielded small reductions in average speed, however high-speed reductions were more successful with the proportion of those travelling at more than $50 \mathrm{kph}$ in the $30 \mathrm{kph}$ limits falling from $7 \%$ to $3 \%$. (Wernsperger and Sammer 1995). In Great Britain the available data suggests similar, modest reductions can be expected. Pre-post scheme data in Portsmouth indicated a reduction in the average speed from $19.8 \mathrm{mph}$ to $18.5 \mathrm{mph}$ (Atkins, 2010). Early data from two pilot trials in the city of Bristol found a $1.4 \mathrm{mph}$ and $0.9 \mathrm{mph}$ reduction in average daytime speeds in both pilot areas (Bristol City Council 2011). This and other data led the Department for Transport (2013) to conclude that 'research into signed-only $20 \mathrm{mph}$ speed limits shows that they generally lead to only small reductions in traffic speeds', and - perhaps of concern to advocates of $20 \mathrm{mph}$ limits - the 
Department guidance seemed to accept non-compliance in recommending that 'signed-only $20 \mathrm{mph}$ speed limits are therefore most appropriate for areas where vehicle speeds are already low'.

If cutting limits by $10 \mathrm{mph}$ only generates average speed reductions of $1-2 \mathrm{mph}$ it logically follows that speed limits are being widely violated. European data suggested at least $50 \%$ of motorised traffic routinely violates speed limits (Elvik, 2012, European Transport Safety Council 2010); and Stradling, Broughton, Kinnear, O'Dolan, Fuller, Gormley et al's (2008) study of UK drivers found a third admitting to a speed of $35 \mathrm{mph}$ within $30 \mathrm{mph}$ limits three or more times per week, with $11 \%$ per cent of drivers admitting to driving at $40 \mathrm{mph}$ on a $30 \mathrm{mph}$ road.

What are the underlying causes of drivers' non-compliance with speed limits? In reviewing these we begin by examining the likely extent and nature of public support, before focusing more directly on driver behaviour.

\subsection{Public support and opposition for $20 \mathrm{mph}$ limits}

Public support for speed limits is clearly important for a policy of self-enforcement to work. 'Headline support' does not seem to be a problem. We have already noted the consistently high levels of international support for speed limits across a range of roads. This support extends to $20 \mathrm{mph}$ limits in GB with typically over $70 \%$ support recorded (e.g. British Social Attitudes Survey for the Department for Transport 2012). Focus group work showed some concern with negative impacts on pollution and difficulty of driving at that speed, but support for $20 \mathrm{mph}$ limits increased as the discussion progressed (Musselwhite, Avineri, Susilo, Fulcher, Bhattachary and Hunter 2010).

Arguments for and against $20 \mathrm{mph}$ limits seem ongoing. Majority support has survived but remains under continuous challenge. 'Establishment experts' in the media may espouse the benefits of lowered residential speed limits, but the public acceptance of 'expert' (including academic expert) advice has declined, an effect noted in the road safety field by Wells (2012). In addition, while opposition voices may only form a small minority, they tend to be vocal, well organised, and given a platform by a willing media that thrives on oppositional debate (an effect also noted by Wells with respect to speed camera debates). However it is unclear how influential these arguments have been in shaping opinion and behaviour. Selective absorption of such debates by drivers according to their pre-disposition to speeding is likely. Also unclear, and hence the subject of investigation here, are the priorities of the underlying reasons for support or opposition. One possibility is that of intrapersonal attitude shifts, that is, the same person holding apparently conflicting attitudes depending on the context they occupy at that point, in particular, that people may support $20 \mathrm{mph}$ limits as a 'resident' while opposing them as a 'driver' (see for example Musselwhite, Avineri, Fulcher, Goodwin and Susilo 2010b). This may be another reason that accounts for the widespread 'headline' support for speed limits even while they are widely broken.

\subsection{The dangers of speeding are contested}

One key issue affecting support for speed limits generally is the (publicly) contested nature of the link between speed and danger. This link, and the quantification of it, has been the subject of considerable academic study (Elvik 2005, Aarts and van-Schagen 2006). In their review of studies into the relationship between speed and crash rate, Aarts and van Schagen (2006) found that the majority of reviewed studies found evidence for a power function between speed and crash rate. However, they found that while the relationship between and crash severity once a crash had occurred was clear, the relationship between speed and the risk of a crash was much more complex. 
Hence, professional and academic assessments of speed and its risks are far from universally understood and / or accepted by the public (McKenna 2010, Wells 2012). It is common (even amongst driver trainers) to find the argument that speeding is not risky provided the skill levels of drivers is high enough to handle the speed. Assessing risk also requires accurately assessing probabilities - a calculation most people are poorly equipped to make accurately (Roberts 2013). Crashes are complicated and have multiple causes, and the role of speed in crashes is complicated to unravel and difficult to prove (Elvik 2012). These complexities have to be simplified by drivers making everyday decisions, hence their use of 'availability heuristics' (the tendency to use easily available information to make decisions (Kahneman 2011)) in deciding that 'speeding today is safe' because 'each time I've done this before I have been fine'.

\subsection{Attitudes to law breaking}

Levels of support or opposition to speed limits are affected by drivers' attitudes to breaking or complying with laws in general, and speeding laws in particular. This manifests itself in resistance by 'law-abiding' citizens (94\% of drivers see themselves as law abiding (Musselwhite et al 2010b)) being labelled as law breakers. Wells $(2012, \mathrm{ch} 2, \mathrm{ch} 5)$ explored attitudes to speeding laws and found that the label of a 'law-breaker' created anxiety (fear of being caught) and anger (if caught) and the response was to reject the fairness and appropriateness of the law. This was compounded by the enforcement of speed limits as strict liability (proof of intent is not needed to prosecute) hence adding to the frustration and sense of unfairness (Wells 2012 p34). Another manifestation of attitudes to laws comes from drivers whose high confidence in their own skills, and high need for personal autonomy and control in deciding their own driving decisions, leads them to conclude that speed limit laws should not apply to them (Corbett and Simon 1992). These may correspond to Fleiter, Lennon and Watson's (2007) 'regular speeders'; in contrast 'rare speeders' felt a moral imperative to comply, and paid strong attention to speed limits.

\subsection{Personal motives lead to personalised limits}

Perhaps the most obvious antecedent of speed is deliberate motive. Thus, despite their public disapproval of speeding, some drivers privately clearly consider speeding to have various benefits. Deliberate (instrumental) motives include exceeding the posted limit because the driver is in a hurry or wants to save time, and speeding as a thrill seeking experience (McKenna 2010). Stradling et al's (2008) UK study of excessive speeders reported typical speeding motives included speeding to overtake, to keep up with the traffic, while driving on empty roads and when running late.

These motives may explain the tendency for speed limits to be seen as malleable rather than fixed. Corbett and Simon (1992b) examined why drivers routinely drive slightly above the speed limit. It emerged that drivers tend to generate personalised 'legal limits': they did not regard speed limits as absolutes, instead creating a personal limit that they felt better expressed the true risks. They did not regard exceeding limits as dangerous, and as long as they felt comfortable and in control, they were morally justified in exceeding speed limits (Corbett and Simon 1992b). Similar findings were reported with Australian and U.S. drivers by Fleiter and Watson (2006) and Mannering's (2009) respectively.

\subsection{Self-enhancement bias}

The phenomenon - common internationally - of simultaneous support and non-compliance for speed limits has been the subject of considerable study. This apparent paradox is widely attributed to the 
tendency for drivers to over-estimate their own driving ability and under-estimate that of others; in consequence, most drivers believe they are 'better than average', and conclude that speed limits are required for 'other drivers' but not for themselves. This effect has been given a number of labels including optimism bias, self-serving bias, and self enhancement bias, and is often attributed firstly to Svenson's (1981) work, with follow up studies from Groeger and Brown (1989), Goszczynska and Roslan, (1989), McKenna, Stanier and Lewis (1991) and Delhomme (1991) amongst others.

McKenna's (1993) study attributed these unrealistic risk assessments to an 'illusion of control' (a belief of personal control over events that, in reality, is not merited) as opposed to an 'unrealistic optimism' (a general, unmerited expectancy of a positive outcome). More recent studies in the UK from Horswill, Waylen and Tofield (2004) and McKenna (2007b) found that British drivers who rated themselves as more skilful also reported faster driving speeds. Clearly there will be a concern that this phenomenon creates a large constituency of drivers who might feel $20 \mathrm{mph}$ limits don't need to apply to them- hence this was a particular focus for this study.

\subsection{Copycat and normative effects of other drivers on one's own driving}

Connelly and Aberg (1993) described a social contagion model in which drivers adopt speeds according to comparisons made with the speed of others on the road. In the U.K. one third of drivers said they would drive faster if the traffic is moving faster than they normally travel at (Stradling, Campbell, Allan, Gorrell, Hill, Winter et al 2003). Unfortunately this social contagion can combine with the tendency of drivers to over-estimate speeds of other drivers to create 'distorted' norms that influence driving (Musselwhite et al 2010b). This false consensus effect was also found in Sweden by Haglund and Aberg (2000) who found that speeding was overestimated to a large extent as a result.

In their exploration of social contagion Corbett and Simon (1992) found the need to conform and to avoid social pressures of not conforming were important motives, again, an effect noted elsewhere by Fleiter, Lennon and Watson (2010) who found drivers felt pressures to 'keep up with traffic' and to conform to a perceived consensus. Corbett (2001) noted the perceived dangers of driving at variance with the mean speeds on a road, leading to the paradoxical conclusion that driving more slowly than a speed limit (in which the mean speed was higher than that limit) may be regarded as more unsafe than exceeding the limit themselves, hence providing a moral rationale for exceeding limits. The concern for advocates of $20 \mathrm{mph}$ limits may be that group pressures such as these may be in play and may even be exacerbated in $20 \mathrm{mph}$ limits imposed on roads whose design may encourage faster speeds.

The pressure to 'fit in' with other motor traffic also arises from negative stereotypes and stigmas that can be attached to non-mainstream driving styles. Corbett (2001) raised the popular stereotypes of slow drivers (travelling below the mean speed) as old, under-confident, unpredictable, short-sighted, and low-skilled that also makes normative pressures to 'keep up' with traffic considerable. These contrast with media and marketing portrayals of faster driving as confident, skilful or even glamorous, possibly influencing drivers to speed (albeit tempered by yet another driver stereotype, that of the 'road hog' whose aggressive, too-close driving is popularly regarded as socially unpleasant or dangerous). Finally, we note that in-car influences on driving from passengers can also be significant (Silcock, Smith, Knox and Beuret 1999; Conner, Smith and McMillan 2003; Thomas, Kavanagh, Tucker, Burchett, Tripney and Oakley 2007). Silcock et al (1999) 
found a majority of drivers who admitted driving differently (this may mean both more safely and more riskily) with others in the car.

These social contagion, peer and normative influences were identified as important in a $20 \mathrm{mph}$ limit context by Toy, Tapp, Musselwhite and Davis (2014); these effects were combined with the effects of car gearing and road design to lead some drivers to conclude that adhering to new $20 \mathrm{mph}$ limits will be difficult.

\subsection{Driving automaticity}

In their study of drivers caught speeding Simon and Corbett (1991) found two distinct types: firstly, 'deliberate speeders' who were aware that they exceeded the limit and believed it safe to break the speed limit; and secondly, 'inadvertent speeders', who either did not know there was a speed limit in force, or had not realised how fast they were going. The same authors (Corbett and Simon 1992b) studied attitudes to speeding at over $40 \mathrm{mph}$ in a $30 \mathrm{mph}$ limit and found $46 \%$ claimed to speed 'without realising it'. Such habitual or 'automatic' (inattentive/inadvertent) driving has once again been observed in many countries (Forward 2009; De-Pelsmacker and Janssen 2007). Recarte and Nunes (2002) and McKenna (2010) found that inattentive speeding may be governed by perceptual cues (such as the width of the road, the quietness of the car at speed, and speed perceptions distorted by long travel at high speeds on motorways) that transmit risk levels, with signposted speed limits ignored or downplayed.

\subsection{The JIMBY effect}

Of particular interest to compliance in $20 \mathrm{mph}$ limit areas is the 'Just in my back yard' JIMBY effect. This was identified as a specific threat to $20 \mathrm{mph}$ limit compliance in the qualitative work of Toy et al (2014). The JIMBY effect, labelled for its opposing dimensionality to the well known "NIMBY" (not in my back yard) effect, refers to the tendency of drivers to drive slowly on roads within their own neighbourhood but faster elsewhere.

Table 1 summarises the various effects reviewed above that formed part of this study.

\section{Table 1: Summary of effects identified and used to explain findings here}

The next section details the methodology used in our research.

\section{Methodology}

\subsection{Objectives of the survey}

The survey had a number of objectives reported on here:

- levels of support and opposition to $20 \mathrm{mph}$ speed limits by drivers

- the reasons for support or opposition

- the extent to which drivers claim they may or may not comply with $20 \mathrm{mph}$ limits

- the nature of the interactions between support/opposition and compliance/non-compliance

- the effect of other motorists on a driver's speed

- attitudes to driving and speed limits, and how these might affect behaviour 


\subsection{Fieldwork and sample}

The survey was administered by YouGov, a reputable and well established polling and research company that is regularly used by government, charity and university sectors. The sample of 3074 respondents were randomly chosen from a large on-line panel, with the sample profiled to fit the Census derived demographics of the GB population. A probability (stratified random) technique of sampling was used to permit statistical inference. The sample further yielded 2297 respondents who responded as drivers of some form of motor vehicle. The effective sample size, i.e. the sample size that is permissible for statistical tests after weighting procedures was 2219. Fieldwork was undertaken between 09/07/2013 - 22/07/2013.

On-line surveys have various advantages, not least favourable costs and rapid fieldwork time that enabled a large sample to be obtained. In addition, respondents could answer questions in their own time without being pressured. Importantly, there is also evidence that on-line surveys reduce socially desirable responding effects. (See Nancarrow and Tapp (2014) and the references therein for an in-depth evaluation of on-line panels).

\subsection{Questionnaire and analysis}

Measures of attitudes and behaviours were undertaken through agreement with scale items, for example If I think a road with a $20 \mathrm{mph}$ limit is clear I will be more likely to drive more quickly than 20 mph; On occasions, I knowingly drive faster than speed limits where I think I can do so safely. Five point Likert scales were used with the exception of the 'support-oppose' question that used a quasi forced-choice approach via a four point scale with a 'don't know' option. The support-oppose question was placed early within the survey in order to avoid it being affected by the other scales that might introduce issues respondents had not thought of beforehand (in other words, allowing the survey to inadvertently act as an education vehicle to colour opinion). Where appropriate scale response options were randomised in terms of the order presented to respondents. Finally, the reader should note that in the presentation of data below the phrase 'net agree' is the sum of those who 'strongly agree' + 'tend to agree'. Likewise 'net disagree' is the sum of 'strongly disagree' + 'tend to disagree'.

\section{Results}

In this section we isolated those within the sample who supported or opposed $20 \mathrm{mph}$ limits, and then further split these two groups according to whether they would comply or not comply with the limits when driving. This created four groups: supporters who complied, supporters who did not comply, opponents who complied, and opponents who did not comply. Table 2 illustrates these groups, with the percentage figures indicating the proportion of the each group makes of the fourgroup total.

\section{Table 2: Summary of effects identified and used to explain findings here}

\subsection{Supporters of $20 \mathrm{mph}$ limits}

This section focuses on respondents who agreed that they supported $20 \mathrm{mph}$ in residential areas. Within these supporters we examined two groups differing with regard to compliance based on the statement "If a 20mph limit is introduced I may not stick to it": 
- those who support 20mph but agree with the above statement, called "supporter-noncompliers"

- those who support 20mph and disagree with the statement, called "supporter-compliers"

The supporter-non-compliers are of particular interest given the apparent contradiction in their support for $20 \mathrm{mph}$ limits but unwillingness to comply with the limits themselves. In other words, their behaviour appears to contradict their attitude with respect to $20 \mathrm{mph}$ limits. To establish why this may be the case we examined a variety of claimed attitudes, behaviours and demographics to establish how the two groups differ. In the discussion section later we discuss the implications for behaviour changes.

We start with Table 3, examining supporters' compliance and non-compliance. First we should note in Table 3 the important differences in strength of feelings with respect to support for $20 \mathrm{mph}$ limits. Supporter-compliers hold noticeably stronger views (chose the 'strongly support' option), while in contrast the supporter-non-compliers are much more likely to offer only weak support for $20 \mathrm{mph}$ limits. Moving to strength of feeling with regard to compliance, we see that supporter-noncompliers largely 'tend to agree' rather than 'strongly agree' that they may not stick to $20 \mathrm{mph}$ limits. This may suggest that non-compliers who support $20 \mathrm{mph}$ limits may be open to persuasion. However, the qualified agreement might simply mean that these drivers are reserving their position: they judge each situation in terms whether they risk breaking the law.

\section{Table 3: Examining supporters' compliance or non-compliance here}

Turning to Table 4, we can now examine the differing attitudes of supporter-compliers and supporter-non-compliers in detail. Table 4 shows how supporter compliers and supporter-noncompliers differ most in terms of their attitudes to driving and speed limits. The table starts with the statements where the differences between these two groups are largest and then shows the statements in an order that reflects diminishing differences. The order of our comments below likewise reflects the table - noting where the differences are the greatest and then noting in descending order smaller differences.

Thus, supporter-non-compliers are much more likely to express personal confidence in their own judgement of appropriate speeds (items 1, 3, 4): If I think a road with a $20 \mathrm{mph}$ limit is clear I will be more likely to drive more quickly than $20 \mathrm{mph}$; On occasions, I knowingly drive faster than speed limits where I think I can do so safely; I use my own judgement, not speed limits, to decide on my speed on the road. These items may relate to the illusion of driving superiority noted earlier. Somewhat in contrast, the same group, supporter-non-compliers, are also considerably more likely to opine that... It is just too difficult to stay at $20 \mathrm{mph}$ (item 2) with this 'difficulty' probably attributed to road design, car gearing, and other traffic pressures (Toy et al 2014).

Within the next (lower) level of differences between the two groups we note that supporter-noncompliers are prone to inattentive or habitual/automatic driving in that they are less likely than supporter-compliers to pay much attention to speed limits or be aware of speed limits (items 5, 6). This may to some extent reflect a driving style based on other drivers rather than on speed limits (item 7 once again: I tend to drive at the speed of other people on the road). 
The next tier of differences refers to the perceived (lack of) benefits of $20 \mathrm{mph}$ limits (items $8,10,11$ ): non-compliers agreeing that $20 \mathrm{mph}$ limits are a good idea in theory but are unlikely to make a worthwhile difference; $20 \mathrm{mph}$ limits are an example of the nanny state and compliers believing that $20 \mathrm{mph}$ speed limits should be the norm everywhere in residential areas. These explain the lack of support offered to $20 \mathrm{mph}$ limits amongst supporter-non-compliers. In contrast the following tier of items reflect the often strong beliefs held by supporter-compliers (items 13, 14, 17 and 18...Breaking speed limits is not acceptable in most circumstances, I wish everyone would slow down a bit on the roads, etc).

Standing on its own, item 15, I tend to drive slowly near where I live, but not so much in other residential areas, measures the 'JIMBY' (just in my back yard) effect. Not surprisingly given its arguably socially indefensible nature, admittance of this behaviour is small, but still noticeably larger amongst supporter-non-compliers than supporter-compliers. The high levels of agreement from both groups with Item 18, most people drive too quickly, may be linked to the false consensus effect: the common finding that calculations of average traffic speeds by people are found to be higher than the objectively observed reality.

Table 4: Examining the attitudes of supporters who comply versus supporters that do not comply here

\subsection{Reasons for support}

The analysis of supporters of $20 \mathrm{mph}$ limits is completed with a closer look at the reasons why respondents say they support the new limit (Table 5). As we can see in Table 5, supporters as a whole are most inclined to support $20 \mathrm{mph}$ limits because the limits may mean fewer serious accidents on the roads, and mean children can play more safely. Supporter-compliers are as one might expect more inclined to think this. Interestingly supporter-compliers differ from supporternon-compliers in that they are much more likely to appreciate benefits such as make our streets more pleasant to live in, and improve the quality of life. This suggests that the priorities of supportercompliers seem to lie with residency based benefits as well as driver centric safety/traffic concerns.

\section{Table 5: Reasons for support amongst supporters split by compliance / non-compliance here}

Further light may be shed on these differences by examining the incidence within each group of gender, age and annual mileage driven. Table 6 shows how supporters who may comply are more likely to be women, older age bracket, and driving lower mileages, suggesting that these segments of society have priorities associated with residency rather than driving/traffic concerns.

\section{Table 6: Supporter and opponent group descriptors here}

\subsection{Opposition to $20 \mathrm{mph}$ limits}

We now turn to an analysis of those who say they oppose $20 \mathrm{mph}$ limits. In the same vein as the analysis above, it is noted that $20 \mathrm{mph}$ limit 'opponents' can be split into two, those who oppose but may comply (hereon called opponent-compliers) with the limit, and those who oppose and may not comply (opponent-non-compliers) with the limit. In this case, once again we have a group, opponent-compliers, whose claimed behaviour appears, on the surface, to be at odds with their attitude to $20 \mathrm{mph}$ limits. To establish why this may be the case we examine these two groups' attitudes, behaviours and demographics using the data in Tables 7-9. As we see in Table 7, both 
opponent-compliers and opponent-non-compliers tend to register mild rather than strong opposition to $20 \mathrm{mph}$ limits. Opponent-non-compliers are also more likely to register only mild agreement that they may not comply: this contrasts with the strong feelings about pro-compliance expressed by those who support and may comply. Non-compliance levels may therefore be open to change, but clearly remain a greater challenge to change than supporters of the limit.

Table 7: Examining opponents' compliance or non-compliance here

To understand these responses in more detail the reader is referred to Table 8 which illustrates how opponent-compliers and opponent-non-compliers differ most in terms of their attitudes to driving and speed limits. As with Table 4, the table starts with the statements where the differences between these two groups are largest and then shows the statements in an order that reflects diminishing differences. Once again, the order of our comments below likewise reflects the table noting where the differences are the greatest and then noting in descending order smaller differences.

Item 1, I will be careful to observe new 20 mph limits wherever they are, confirms the strong intention of opponent-compliers to obey the speed limits. Opponent-compliers may be primarily defined by their unwillingness to personally break the law, with this unwillingness over-riding their opposition to $20 \mathrm{mph}$ speed limits. Thus opponent-compliers seem to believe that laws (perhaps of any type) should be obeyed even if the premise behind the law is disapproved of. Their strong agreement with Item 9, breaking speed limits is not acceptable in most circumstances, offers further evidence for this.

In contrast, opponent-non-compliers were much more likely to strongly agree with Items 2-4: If I think a road with a $20 \mathrm{mph}$ limit is clear I will be more likely to drive more quickly than $20 \mathrm{mph}$; I use my own judgement, not speed limits, to decide on my speed on the road; On occasions, I knowingly drive faster than speed limits where I think I can do so safely. Thus, opponent-non-compliers believe their driving skill enables them to break speed limits.

Item 5: It is just too difficult to stay at $20 \mathrm{mph}$ is clearly an important differentiator. Here, perceived difficulty is unlikely to mean personal 'inability' of opponent-non-compliers given that they are more likely to agree that I am a better than average driver (item 19). As we discussed with regard to supporters earlier, perceived difficulty is likely to be regarded as the effect of other drivers, or the perceived lack of congruence between (both) road and car designs, and 20mph limits.

Finally, items 7 and 8: I tend to unconsciously drive faster than speed limits quite often and I don't much engage with speed limits I just go with the flow refer to the idea of breaking limits 'unconsciously', something many opponent-non-compliers seem to associate with. This may refer to not noticing the limits at all (see also item 17: Most people who break 20mph speed limits don't mean to, they simply didn't notice the limit was 20mph), or being swept along by the speed of others (see also item 12: I tend to drive at the speed of other people on the road).

Clearly these findings have implications for interventions aimed at opponent-non-compliers; we will analyse these implications in the discussion section later.

Table 8: Examining the attitudes of opponents who comply versus opponents that do not comply here 


\subsection{Reasons for Opposition amongst opponents}

Table 9 illustrates the reasons for opposing $20 \mathrm{mph}$ limits, with the \% figures indicating the proportion of opposition, and the \% differences indicating differences of opinion between opponent-compliers and opponent-non-compliers.

Both groups oppose $20 \mathrm{mph}$ limits mainly because they will be ignored by many drivers so of limited benefit and be pointless as many people will ignore them. However opponent-non-compliers are disproportionately concerned that $20 \mathrm{mph}$ limits will increase congestion and make journey times longer. Referring back to Table 5 we can see that these drivers are disproportionately male, younger, and covering higher mileages, and hence presumably more likely to view $20 \mathrm{mph}$ limits through the lens of a car windscreen than as residents.

\section{Table 9: Reasons for opposition amongst opponents split by compliance / non-compliance here}

\subsection{Compliance and non-compliance}

Lastly, we briefly offer a short analysis that reverses the hierarchy of the matrix of compliance/noncompliance, and support/opposition.

\subsubsection{Compliance}

Table 10 examines compliance, split by those who support or oppose $20 \mathrm{mph}$ limits. In contrast to the above tables this time we examined which items received similar responses, thereby identifying what both groups had in common. Thus those items at the bottom of the table, with the lowest differential scores, were of most interest in identifying possible over-riding variables explaining compliance.

The highest commonality of view amongst compliers who are both supporters and opponents of $20 \mathrm{mph}$ lay in their joint agreement (item 4) that breaking speed limits is not acceptable in most circumstances. The other items (1-3) were selected to illustrate that opponent-compliers disagreed with supporter-compliers in most of their attitudes to $20 \mathrm{mph}$ limits: (20mph speed limits should be the norm everywhere in residential areas, 20 mph limits are an example of the nanny state, It is just too difficult to stay at 20 $\mathrm{mph}$ ) but that their belief in the importance of following rules or obeying laws appears to over-ride their personal opposition to that law.

Table 10: Compliance with 20mph limits here

\subsubsection{Non compliance}

Similarly, there are some non-compliers who surprisingly support $20 \mathrm{mph}$ limits, while others more logically oppose. Hence, Table 10 examines non-compliance, split by those who support or oppose $20 \mathrm{mph}$ limits, to examine what explains their (non-complying) commonality.

Here, commonality (once again items (3-5) towards the bottom of the table with low \% differences between the two groups) can be seen in very similar claimed driving styles: I tend to drive at the speed of other people on the road; I tend to unconsciously drive faster than speed limits quite often and I use my own judgement, not speed limits, to decide on my speed on the road. Non-compliance is therefore seemingly primarily associated with inattentive driving, 'socially contagious' driving, and with self-enhancement bias in assessing their own driving ability. 
Sharp differences (items 1 and 2) are once more noted in attitudes to $20 \mathrm{mph}$ limits, for example: $20 \mathrm{mph}$ speed limits should be the norm everywhere in residential areas; $20 \mathrm{mph}$ limits are an example of the nanny state.

\section{Table 11: Non-compliance with 20mph limits here}

\section{Discussion}

For those charged with designing behaviour change interventions to maximise compliance with $20 \mathrm{mph}$ limits, two questions arise: first, which group or groups should be prioritised for targeted change? Secondly, what specific intervention designs are most appropriate?

Regarding the first question, Figure 1 summarises the key differences in attitude and behaviour amongst the four groups in our support/opposition and compliance/non-compliance matrix.

From the perspective of behaviour change, supporter-compliers appear to be advocates of the new limits and, arguably, need not be the subject of any specific persuasion; at the other end of the spectrum opponent-non-compliers would be a key target, albeit presenting many challenges. The other two groups, supporter-non-compliers and opponent-compliers pose somewhat more subtle challenges. However, in terms of societal priorities it seems clear that supporter-non-compliers are a more important target for change than opponent-compliers. Raising compliance levels would help achieve the social objectives of $20 \mathrm{mph}$ limits, irrespective of the attitudes of these drivers. In addition, driven by the influence of descriptive norms effects (i.e. people are influenced to behave according to everyday behaviours of others - see Cialdini (2007) for examples across different contexts) a virtuous circle of more compliance encouraging others could result. By this logic, the emphasis should be more on compliance and less on support; the priority groups in Figure 1 are therefore those in the two right-hand boxes: those who support but may not comply, and those who oppose and may not comply. Of these, it is presumed that supporter-non-compliers will prove more open to persuasion in addressing their driving styles than opponent-non-compliers.

Figure 1: Summary of key attitudes and behaviours that differentiate each group here

Moving now to the subject of intervention designs, Table 12 proposes a list of possible solutions for these non-complying groups. These solutions reflect in particular the finding of Table 11: that sharp differences in attitude may differentiate supporters and opponents of $20 \mathrm{mph}$ limits but these attitudes appear to have little or no effect on the driver behaviour of the supporter-non-complier group. To put this point another way, supporter-non-compliers de-couple their personal driving (non-compliance) from their apparent support for $20 \mathrm{mph}$ limits. The problems and proposed strategies listed in Table 12 therefore tend to focus on specific driving behaviours and their causes rather than on attitudes.

(Note that the priority order of these issues and possible strategies should be regarded as quite tentative: the order reflects a qualitative assessment by the authors of the possible importance of the influence of the items in Tables 3-11 on behaviour).

In general, our proposed strategies reflect the conclusion of Musselwhite et al (2010b) that engineering and enforcement alone are unlikely to fully address the deeply social/psychological nature of speeding behaviour. If we examine the list of problems in Table 12, it may be argued that many of these (normative pressures, copycat behaviours, narrative stereotypes of driving) are social 
rather than individual in nature, and hence that a socially located 'environment of disapproval' of speeding in $20 \mathrm{mph}$ areas is required. On the other hand the key issue of self-enhancement bias may be best tackled via individualised approaches. A two pronged attack that deploys both socially located and individualised strategies may therefore be required: both strategies are discussed now, with Table 12 also offering selected examples to illustrate the kind of tactics that may ensue.

Table 12: Causes of non-compliance and proposed strategies, in priority order here

We first discuss social/public campaigning. 'Speed kills' styles of campaign have been at least partially successful in changing publicly shared attitudes of social disapproval, and indeed can be accepted by some speeders as relevant to them (Walton and McKeown 2001). However it seems that these messages may still be all too easily filtered out by many speeders' self-enhancement biases. The knock-on effect of so many drivers routinely speeding is that speeding becomes normalised and no stigma is associated with speeding. The challenges to the use of social advertising in generating a sense of social unacceptability for speeding are therefore considerable. Perhaps the widespread dismay from residents at speeding in one's own local area (Poulter and McKenna 2007) allows an entry point for a renewed attack on the social acceptability of speeding in $20 \mathrm{mph}$ limit areas.

Signs of hope in challenging speeding cultures emerge from Wells' $(2012$, ch.2) review of the history of speed limits in the UK which clearly showed that attitudes to laws change over time, while McKenna (2007 p174) noted that 'the perceived legitimacy of [road safety] interventions [laws] can change considerably over time and interventions that were not considered legitimate at one point in time may be considered uncontroversial in another point in time'. At the moment, non-compliers regard speeding as 'legitimate', that is, as a socially acceptable way of behaving. Simultaneously, attempts to strictly enforce speed limits are often regarded as not legitimate, for example with speed cameras regarded as revenue raising 'scams' for local authorities. Ideally, from the perspective of compliance, these perceived legitimacies need to be reversed so that speeding is regarded as unacceptable, and speed enforcement is regarded as justified. These twin tasks create a possible long term role for educational campaigns about the dangers of speeding that have been criticised as generally ineffective at directly changing behaviour (Roberts and Kwan 2008, McKenna 2010b). Instead, an indirect (that is, long term, facilitating other more direct approaches) role for educational campaigns could be to facilitate the perceived legitimacy of speed limit enforcement. Improving the perceived legitimacy of enforcement may also be achieved by increasing the prevalence of speed awareness courses and reducing fines, or campaigns that explain how revenues from fines are spent (McKenna 2010b).

A more ambitious agenda might involve critical exposure (public critiques of the culture of acceptability of speeding) as a way of instigating a macro-culture change in attitudes to make speeding socially unacceptable. This is by no means a new idea (see for example Whitman and McKnight's (1985) debate on injury prevention and ideology) but the rise in interest and acceptability of $20 \mathrm{mph}$ limits with their concomitant implications of a possible shift against car dominant cultures, at least in urban settings, suggests that a tipping point of favourability towards a new ideology of low speeds (Tranter 2010) may no longer be unrealistic.

Whatever the merits of culture change strategies, the complex causes of non-compliance identified in Table 11 suggest that for rapid behavioural improvements in driving, a shift in approach from the 
'general' to the 'personal' will also be required. It remains far too easy for people to excuse themselves from any messages about dangerous speeding: 'these messages are for others not me'. Personal, one-one demonstrations of one's own limitations - perhaps through regular testing or incar training - may be more powerful than generalised demonstrations in cutting through erroneous beliefs in one's own superior skills. In this context in-depth, personalised training courses show promise (Helman 2012) but would require a paradigm shift (for example compulsory re-training every five years) as opposed to drivers used to 'passing their test' and a lifetime's driving that this currently awards them. Targeting drivers who exceed speed limits offers an alternative and possibly more realistic route, especially given the public acceptability of 'speed awareness courses'. The latter could be adjusted to include an element of in-car training and feedback which has shown recent promise for reducing risky driving behaviours (Tapp, Pressley, Baugh and White 2013). The big divide between 'residents' and 'drivers' may be bridged through 'community speedwatch' programmes in which local people can demonstrate their disapproval for speeding with officially sanctioned use of speed monitoring equipment.

A shift in content for interventions may also be required. Rather than merely emphasising the physical dangers of speeding, content could include discussions of self-enhancement bias, social contagion effects, distorted norms from over-estimating others' speed, personalised speed limit effects, and so on. This idea is by no means new: Corbett and Simon (1999) came to a similar conclusion after their work researching driver responses to automated enforcement of speed. Confronting these psychological and social psychological effects head-on in a discussion based approach may offer people insights that they can use to change their own behaviour.

\section{Conclusion}

The findings here support a model of driver speeding that offers considerably more complexity than simple mechanisms of attitudes predicting behaviour. A number of discriminators of the dimensions of support-opposition and compliance-non-compliance with respect to $20 \mathrm{mph}$ speed limits in GB have been identified. Key discriminators included self-enhancement bias, social contagion, and inattentive/automatic driving. There seemed to be a de-coupling of attitudes and behaviour such that high numbers of drivers apparently contradict their support or opposition for $20 \mathrm{mph}$ limits with their actual driving.

These issues must be of concern to those who advocate low residential-area speed policies, and intend to implement these through signs-only limits. Lack of resources for enforcement, and (some) public resistance to strict enforcement, has meant that speed limit reductions have only created modest average reductions in speed. These findings suggest that designers of $20 \mathrm{mph}$ limits (and possibly $30 \mathrm{kph}$ schemes internationally) need to include programmes that directly address compliance. In debating such solutions, this paper noted the evidence from elsewhere that suggests that it is highly unlikely that general educational approaches will have any direct impact on behaviour. In lieu of this, and noting the complex, multi-factor challenges to compliance, a twopronged strategy that addresses both the macro (cultures), and micro (social psychology) of speeding may be necessary to embed a driving norm of lower speeds. Whilst the general lack of success of compliance in higher speed roads may serve as a warning of the difficulties ahead, the paradigm shift that $20 \mathrm{mph}$ limits offer for the lives of residents as opposed to drivers may serve as the starting point for a different outcome. 


\section{Acknowledgments}

The authors are very grateful to Bristol City Council for funding the survey.

\section{References}

AAA foundation (2012) The 2012 Traffic Safety Culture Index, available from

https://www.aaafoundation.org/2012-traffic-safety-culture-index

Aarts, I. and van Schagen, I. (2006) Driving speed and the risk of road crashes: a review.

Accident Analysis and Prevention, 38, 2, 215-224.

Atkins (2010) Interim evaluation of the implementation of 20mph speed limits in Portsmouth. Atkins Global, London. Atkins Transport Planning and Management

Bristol City Council (2011) 20mph speed limit pilot areas. Monitoring Report. December 2011

Cialdini R. (2007) Influence: the psychology of persuasion. HarperCollins, NY

Cohen, J., Boniface, S., and Watkins, S. (2014) Health implications of transport planning, development and operations. Journal of Transport and Health, 1, 63-72.

Conner, M., Smith, N., and McMillan, B. (2003) Examining normative pressure in the theory of planned behaviour: impact of gender and passengers on intentions to break the speed limit. Current Psychology 22, 3, 252-263

Corbett, C. (2001) Explanations for "understating" in self-reported speeding behaviour. Transportation Research Part F: Traffic Psychology and Behaviour, 4, 2: 133-150

Corbett, C. and Simon, F. (1992) Decisions to break or adhere to the rules of the road, viewed from the rational choice perspective. British Journal of Criminology, 32, 4, 537-549

Corbett, C. and Simon, F. (1992b) Unlawful driving behaviour: a criminological perspective.

Contractor report 310. Crowthorne: Transport Research Laboratory.

Corbett, C. and Simon, F. (1999) The effects of speed cameras: how drivers respond. Road Safety Research Report no 11. London: DETR

Delhomme, P. (1991) Comparing one's driving with others': Assessment of abilities and frequency of Offenses: Evidence for a superior conformity of self-bias? Accident Analysis \& Prevention, 23, 6, 493508.

Department for Transport (2012) British Social Attitudes Survey 2011: Public attitudes towards transport. London: Department for Transport

Department for Transport (2012b) Free flow vehicle speed statistics. Released $27^{\text {th }}$ June 2013, London: Department for Transport 
Department for Transport (2013) Setting Local Speed Limits. Circular. DfT 01/2013 London:

Department for Transport

De-Pelsmacker, P., Janssen, W., (2007) The effect of norms, attitudes and habits on speeding behavior: Scale development and model building and estimation. Accident Analysis \& Prevention, 39,1, pp 6-15

Dorling, D. (2014) 20mph Speed Limits for Cars in Residential Areas, by Shops and Schools. Chapter 3 of L. Newby and N. Denison (eds) If You Could Do One Thing: Nine Local Actions to Reduce Health Inequalities. London: British Academy.

Elvik, R. (2005) Speed and Road Safety: synthesis of evidence from evaluation studies. Transportation Research Record: Journal of the Transportation Research Board no 1908. Transportation Research Board of the National Academies, Washington DC; pp59-69.

Elvik, R. (2012) Speed limits, enforcement, and health consequences. Annual Review of Public Health, 33, 225-38

Fleiter, J., Lennon, A. and Watson, B. (2010) How do other people influence your driving speed? Exploring the 'who' and the 'how' of social influences on speeding from a qualitative perspective. Transportation Research. Part F: Traffic Psychology and Behaviour, 13, 1, 49-62.

Fleiter, J., Lennon, A., and Watson, B. (2007) Choosing not to speed: a qualitative exploration of differences in perceptions about speed limit compliance and related issues. Australia: Centre for accident research and road safety.

Fleiter, J. and Watson, B. (2006) The speed paradox: the misalignment between driver attitudes and speeding behaviour. Journal of the Australasian College of Road Safety, 17, 2, 23-30.

Forward, S. (2009) The theory of planned behaviour: The role of descriptive norms and past behaviour in the prediction of drivers' intentions to violate. Transportation Research Part F: Traffic Psychology and Behaviour, 12, 3, 198-207.

Grundy C, Steinbach R, Edwards P, Green J. Armstrong, B. and Wilkinson P. (2009), Effect of $20 \mathrm{mph}$ traffic speed zones on road injuries in London, 1986-2006: controlled interrupted time series analysis, British Medical Journal 339:b4469

Groeger, J., and Brown, I. (1989) Assessing one's own and others' driving ability: Influences of sex, age, and experience. Accident Analysis \& Prevention, 2I, 2, 155-168

Goszczy'nska, M., and Rosyan, A. (1989) Self-evaluation of drivers' skill: A cross-cultural comparison. Accident Analysis \& Prevention, 21, 3, 217-224

Haglund, M. and Aberg L. (2000) Speed choice in relation to speed limit and influences from other drivers. Transportation Research Part F, 3, 1, 39-51 
Helman, S. (2012) Driver training testing and licensing, and the safety of new drivers. Transport Research Laboratory, accessed through:

http://www.roadsafe.com/pool/files/events/youngdriversexpertmeeting/Roadsafe\%20expert\%20m eeting\%202012\%20Shaun\%20Helman.pdf

Horswill, M., Waylen, A., and Tofield, M., (2004) Drivers ratings of different components of their own driving skill: a greater illusion of superiority for skills that relate to accident involvement. Journal of Applied Social Psychology, 34, 1, 177-195.

Hyden, C., Jonsson, T., Linderholm, L. and Towliat, M. (2008) New speed limits in urban areas. Bulletin 240, Lund Institute of Technology, Dept of Technology and Society, Lund.

Islam, M., El-Basyouny, K., and Ibrahim, S. (2014) The impact of lowered residential speed limits on vehicle speed behaviour. Safety Science 62, 483-494.

Kahneman, D. (2011) Thinking, fast and slow. Farrar, Straus and Giroux: New York

Koch, D-L., 2011, Report on European road safety 2011-2020. Report number A7-0264/2011; accessed via:

http://www.europarl.europa.eu/sides/getDoc.do?type=REPORT\&mode=XML\&reference=A7-2011$\underline{0264 \& \text { language }=E N}$

Mannering, F., (2009) An empirical analysis of driver perceptions of the relationship between speed limits and safety. Transportation Research Part F 12, 2, 99-106

McCabe, K., Schoneman, K., and Arcaya, M. (2013) Community Speed Reduction and Public Health: A technical report. Health resources in action. U.S.

McKenna, F., Stanier, R., and Lewis, C. (1991). Factors underlying illusory self-assessment of driving skill in males and females. Accident Analysis \& Prevention, 23, 1, 45-52

McKenna, F. (1993), "It won't happen to me: Unrealistic optimism or illusion of control?" British Journal of Psychology (British Psychological Society) 84, 1, 39-50

McKenna, F. (2007). The Perceived Legitimacy of intervention. A Key Feature for Road Safety. American Automobile Association Foundation for Traffic Safety. Retrieved from http://www.aaafoundation.org/pdf/McKenna.pdf.

McKenna, F. (2007b) Road traffic accidents: human factors. In S. Ayers, A. Baum, C. McManus, S. Newman, K. Wallston, J. Weinman and R. West (eds), Cambridge Handbook of Psychology Health and Medicine. Cambridge: Cambridge University Press.

McKenna, F. (2010) Behavioural research in road safety. Road Safety Congress: Eighteenth Seminar; London: Department for Transport. 
McKenna, F., (2010b) Education in Road Safety - Are We Getting It Right? Report for RAC Foundation. Report Number: 10/113.

Musselwhite, C., Avineri, E., Susilo, Y., Fulcher, E., Bhattachary, D. and Hunter, A. (2010) Understanding public attitudes to road user safety: final report. Road safety research report no. 111. Project Report. Department for Transport.

Musselwhite, C., Avineri, E., Fulcher, E., Goodwin, P., and Susilo, Y. (2010b) Public attitudes to road user safety: a review of the literature 2000-2009. University Transport Study Group; Plymouth.

Nancarrow, C. and Tapp, A. (2014) Online access panels for surveys on public health and epidemiology. UWE on-line paper: http://eprints.uwe.ac.uk/23013/

Pilkington, P. (2000) Reducing the speed limit to $20 \mathrm{mph}$ in urban areas. British Medical Journal 320; 1160

Pilkington, P. (2009) Lowering the default speed limit in residential areas: opportunities for policy influence and the role of public health professionals. Injury Prevention 15; 5, 352-353

Poulter, D. and McKenna, F. (2007) Is speeding a 'real' antisocial behavior? A comparison with other antisocial behavior. Accident Analysis and Prevention, 39, 2, 384-389.

Recarte, M. and Nunes, L. (2002) Mental load and loss of control over speed in real driving: towards a theory of attentional speed control. Transportation Research Part F, 5, 2, 111-122

Roberts, I. (2013) Why improving public health may lead to more injury not less. In Safety, sustainability and future urban transport, ed. Mohan, D., Eicher: New Delhi

Roberts, I. and Kwan I. (2008) School-based driver education for the prevention of traffic crashes. Cochrane Database of Systematic Reviews, Issue 4.

Stradling, S., Campbell, M., Allan, I., Gorrell, R., Hill, J., Winter, M. \& Hope, S. (2003) The Speeding Driver: Who, How and Why? Edinburgh: Scottish Executive Development Department Research Findings No. 170/2003.

Stradling, S., Broughton, P., Kinnear, N., O’Dolan, C., Fuller R., , Gormley, M. and Hannigan B. (2008) Understanding Inappropriate High Speed: A Quantitative Analysis. Road Safety Research Report 93; Department for Transport: London

Silcock, D., Smith, K., Knox, D. And Beuret, K. (1999) What limits speed? Factors that affect how fast we drive. Basingstoke: AA Foundation for Road Research

Simon, F. and Corbett, C. (1991) A small roadside study of drivers caught breaking speed limits. Behavioural Research in Road Safety II (Seminar Proceedings. Transport Research Laboratory PA 2193/92). Crowthome, Berkshire, UK. 
Svenson, O. (1981) Are we all less risky and more skilful than our fellow drivers?, Acta Psychologica, 47, $143-148$.

The European Transport Safety Council (2010) Road safety target in sight: making up for lost time. $4^{\text {th }}$ road safety PIN report Brussels: European Transport Safety Council.

Thomas, J., Kavanagh J., Tucker H., Burchett, H., Tripney, J., and Oakley A. (2007) Accidental injury, risk taking behaviour and the social circumstances in which young people (aged 12-24) live: a systematic review. London: EPPI-Centre, Social Science Research Unit, Institute of Education, University of London

Tranter, P. (2010) Speed kills: the complex links between transport, lack of time and urban health; Journal of Urban Health: Bulletin of the New York Academy of Medicine, 87, 2, 155-166

Tapp, A., Pressley, A., Baugh, M., and White, P. (2013) Wheels, Skills and Thrills: A social marketing trial to reduce aggressive driving from young men in deprived areas. Accident Analysis and Prevention, 58, 148-57.

Toy, S., Tapp, A., Musselwhite, C. and Davis, A. (2014) Can social marketing make $20 \mathrm{mph}$ the new norm? Journal of Transport and Health: in press

Walton, D., and McKeown, P. (2001) Drivers' biased perceptions of speed and safety campaign messages. Accident Analysis and Prevention, 33, 5, 629-640

Wells, H., 2012, The fast and the furious: drivers, speed cameras and control in a risk society, Ashgate: Surrey.

Wernsperger, F. and Sammer, G. (1995) Results of the scientific investigation accompanying the pilot trial of 30kph limit in side streets and 50kph limit in priority streets. 23rd European Transport Forum, PTRC, 1995, Proceedings Seminar G, Traffic Management and Road Safety

Whitman, S. and McKnight, J. (1985) Ideology and Injury Prevention. International Journal of Health Services, 15, 1, 35-46. 